\title{
Eriptosis: mecanismos moleculares y su implicación en la enfermedad aterotrombótica
}

\section{Fernando Manzur-Jattin ${ }^{\mathrm{a}, *}$, Neda Álvarez-Ortega ${ }^{\mathrm{b}}$, Carlos Moneriz-Pretell ${ }^{\mathrm{c}}$, Hugo Corrales-Santander ${ }^{a, d}$ y Kevin Cantillo-García ${ }^{e}$}

\author{
a Centro de Investigaciones Biomédicas. Facultad de Medicina. Universidad de Cartagena, Cartagena, Colombia \\ b Universidad de Cartagena, Cartagena, Colombia \\ c Grupo de Investigación Bioquímica y Enfermedad. Facultad de Medicina. Universidad de Cartagena, Cartagena, Colombia \\ ' Escuela de Medicina, Universidad del Sinú Elias Bechara Zainúm-Seccional, Cartagena, Colombia \\ e Medicina Interna. Universidad de Cartagena, Cartagena, Colombia
}

Recibido el 18 de junio de 2015; aceptado el 15 de septiembre de 2015

Disponible en Internet el 31 de octubre de 2015

\author{
PALABRAS CLAVE \\ Apoptosis; \\ Células sanguíneas; \\ Aterotrombosis; \\ Enfermedades \\ cardiovasculares; \\ Lípidos
}

\begin{abstract}
Resumen
Introducción: La eriptosis se ha descrito como el proceso de muerte celular programada en el eritrocito antes de la senectud. Puede desencadenarse en situaciones como: el estrés osmótico, el estrés oxidativo, la exposición a metales pesados, entre otros factores. Diversos estudios sugieren que los eritrocitos pueden desempeñar un papel activo en la hemostasia normal o anormal en ciertas condiciones en las que se produce perturbación de la membrana de estas células.

Objetivo: Describir los mecanismos involucrados en la eriptosis y su estrecha relación con los procesos de adhesión a la pared vascular que conllevan a la enfermedad trombótica.

Método: Se hizo una revisión narrativa a partir de la literatura encontrada en las bases de datos PubMed y Science Direct utilizando las palabras claves. Se seleccionaron 51 artículos originales, 20 revisiones de la literatura y un estudio de casos, que se ajustaban a las exigencias del objetivo. Se revisaron los resúmenes de forma separada e independiente. Seguidamente se buscaron las publicaciones en el texto completo para la revisión.

Conclusiones: La eriptosis se caracteriza por la disminución del volumen celular, la vesiculación y la translocación del fosfatidil serina hacia la superficie externa de la membrana plasmática. Las alteraciones en la distribución de los fosfolípidos favorecen los procesos de adhesión celular a la pared vascular, conllevando al deterioro de la microcirculación, lo cual puede ocasionar
\end{abstract}

\footnotetext{
* Autor para correspondencia.

Correo electrónico: fmanzur1954@hotmail.com (F. Manzur-Jattin).
} 
importantes trastornos a nivel cardiovascular. La comprensión y el esclarecimiento de la eriptosis pueden ser esenciales para la búsqueda de nuevas dianas terapéuticas, encaminadas a ofrecer otras alternativas farmacológicas en el tratamiento de la enfermedad cardiovascular. (c) 2015 Sociedad Colombiana de Cardiología y Cirugía Cardiovascular. Publicado por Elsevier España, S.L.U. Este es un artículo Open Access bajo la CC BY-NC-ND licencia (http:// creativecommons.org/licencias/by-nc-nd/4.0/).

\section{KEYWORDS}

Apoptosis; Blood cells; Atherothrombosis; Cardiovascular diseases; Lipids

\section{Eryptosis: molecular mechanisms and their implications in atherothrombotic disease}

\begin{abstract}
Introduction: Eryptosis has been described as programmed process of cellular death in erythrocytes before old age. It can be triggered, among other factors, by situations such as osmotic stress, oxidative stress or exposure to heavy metals. Several studies suggest that erythrocytes can play an active role in normal or abnormal haemostasis in certain conditions where the membrane of these cells is perturbed.

Objetive: To describe the mechanisms involved in eryptosis and their close relationship with the processes of adhesion to the vascular wall that entail the thrombotic disease.

Methods: A narrative review was carried out from the literature found in data base PubMed and Science Direct by using the key words. 51 original articles, 20 literature reviews and one case study complying with the requirements were selected. Abstracts were reviewed separately and independently. Complete publications were then located for review.

Conclusions: Eryptosis is characterised by the decrease in cell volume, the vesiculation and the translocation of phosphatidylserine towards the outer surface of the plasma membrane. Disorders in the distribution of the phospholipids favour processes of cell adhesion to the vascular wall, causing impairment of microcirculation, which can result in important cardiovascular diseases. Understanding and clarifying eryptosis could be essential for finding new therapeutic targets, aimed at offering other pharmacological alternatives for the treatment of cardiovascular diseases.

(c) 2015 Sociedad Colombiana de Cardiología y Cirugía Cardiovascular. Published by Elsevier España, S.L.U. This is an open access article under the CC BY-NC-ND license (http:// creativecommons.org/licenses/by-nc-nd/4.0/).
\end{abstract}

\section{Introducción}

Los eritrocitos constituyen la mayoría de los componentes celulares de la sangre. Su participación en la hemostasia y en los procesos trombóticos no está claramente comprendida. No obstante, muchos estudios clínicos han reportado una estrecha relación entre el número de eritrocitos con los tiempos de coagulación y la aparición de enfermedades trombóticas ${ }^{1,2}$. Por ejemplo, la prolongación de los tiempos de la coagulación puede ser tratada con la transfusión de eritrocitos ${ }^{3}$. Los pacientes con policitemia vera, a menudo experimentan aumento de trombosis, encontrándose el aumento en el recuento de eritrocitos como un marcador predictivo para su aparición ${ }^{4}$.

Los eritrocitos están desprovistos del núcleo y las mitocondrias, por tanto, carecen de la maquinaria biológica necesaria para realizar el proceso clásico de muerte celular programada o apoptosis ${ }^{5,6}$. Sin embargo, investigaciones realizadas sugieren que estas células pueden sufrir un mecanismo similar a la apoptosis antes de su senescencia ${ }^{7}$, denominado actualmente "eriptosis" 8 . Por otra parte, diversos reportes indican la relación de este evento con los procesos de adhesión a la pared vascular ${ }^{2,9-11}$.

Estos hallazgos sugieren que los eritrocitos pueden desempeñar un papel activo en la hemostasia normal o anormal en ciertas condiciones en las que se produce perturbación de la membrana celular de estas células. En esta revisión se describen los mecanismos moleculares involucrados en la eriptosis al igual que la influencia de los fosfolípidos en los procesos de adhesión a la pared vascular, sus implicaciones en la trombosis y otras patologías.

\section{Metodología}

\section{Estrategia de búsqueda de la información}

Fue realizada una búsqueda en las bases de datos, donde se incluyeron diferentes tipos de publicaciones tales como: artículos originales, artículos de revisión y estudio de casos sobre la eriptosis, además, de enfermedades cardiovasculares relacionadas con los eritrocitos. La búsqueda bibliográfica se realizó por medio electrónico en las bases de datos PubMed y Science Direct.

\section{Métodos de revisión}

Se evaluaron los títulos de los artículos encontrados. En el caso de relacionarse con el objetivo de la revisión, fueron analizados todos los resúmenes de los artículos identificados 
con la finalidad de realizar una nueva selección. Finalmente, los artículos seleccionados fueron revisados en su totalidad.

\section{Recopilación y análisis de datos}

Se identificaron 225 artículos utilizando las palabras claves, de los cuales 72 fueron considerados por su pertinencia a la revisión temática. De éstos, 51 artículos eran artículos originales, 20 revisiones de la literatura y un estudio de casos, que se ajustaban a las exigencias del objetivo. Se revisaron los resúmenes de forma separada e independiente. Seguidamente, se buscaron las publicaciones con el texto completo y se citaron a lo largo de la revisión.

\section{Mecanismos moleculares de la eriptosis}

La eriptosis es un mecanismo de muerte programada de eritrocitos en el que se producen alteraciones en la membrana, como externalización de la fosfatidilserina (PS) y generación de microvesículas, que pueden permitir a los eritrocitos participar en los procesos de: coagulación sanguínea, adhesión celular y eliminación de eritrocitos inmaduros ${ }^{2,8}$. Diversos estudios han descrito la exposición de la fosfatidilserina en la cara externa de la membrana como un marcador de muerte eritrocitaria ${ }^{8,12-15}$. La exposición de ésta proporciona un sitio de ensamblaje para el complejo enzimático protrombinasa y tenasa, lo cual conduce a la generación de trombina, incremento en la coagulación sanguínea y aumenta la probabilidad de eventos trombóticos ${ }^{16-18}$. También, se ha descrito que estos eritrocitos se unen con más facilidad a las células endoteliales contribuyendo a una mayor vaso-oclusión ${ }^{19}$.

La eriptosis es un proceso coordinado de eliminación de células defectuosas, en la cual no hay ruptura de la membrana celular ni liberación del material intracelular. Se caracteriza por la pérdida de la asimetría de la membrana celular y la reorganización de los fosfolípidos ${ }^{14,15}$. Normalmente, en la membrana plasmática del eritrocito, la esfingomielina y la fosfatidilcolina se encuentran en la cara externa de la bicapa de la membrana, mientras que la fosfatidiletanolamina y la fosfatidilserina se encuentran en el interior $^{16}$. La exposición de este último a la superficie celular y la generación de microvesículas procoagulantes en los eritrocitos, está mediada principalmente por el aumento de iones de calcio intracelular ${ }^{7,20}$, con la consecuente activación de la proteína quinasa $\mathrm{c}(\mathrm{PKC})^{21}$.

La eriptosis puede ser estimulada principalmente por el estrés osmótico, el oxidativo y el energético (fig. 1) ) $^{22-24}$; aunque los patógenos intracelulares, los metales pesados como: el mercurio $(\mathrm{Hg})$, el cadmio $(\mathrm{Cd})$, entre otros, también pueden incidir en dicho proceso ${ }^{13,25-28}$. El aumento de los niveles de iones del $\mathrm{Ca}^{2+}$ libre intracelular conllevan a la activación de $\mu$-calpaína, una endopeptidasa cisteínica que degrada las proteínas del citoesqueleto; por tanto, se inicia la formación de vesículas en la membrana celular con la consecuente activación de la eriptosis ${ }^{5,6,29}$. Los eritrocitos cambian su morfogía al perder la simetría de la membrana celular. En un eritrocito que expone la fosfatidilserina en su membrana celular, la forma normal discoide de esta célula puede pasar a diferentes formas que conllevan a la microvesiculación de la membrana plasmática (fig. 2) 2,30.
Aunque la muerte programada de los eritrocitos ha sido planteada como un mecanismo de escape ante la hemólisis, otros estudios han dilucidado el papel de los eritrocitos eriptóticos en el deterioro de la microcirculación ${ }^{31,32}$. En la circulación, los glóbulos rojos están continuamente expuestos a fuentes endógenas y exógenas de especies reactivas de oxígeno que pueden generar daño estructural y alterar su función ${ }^{33}$. La eriptosis se activa como respuesta al estrés oxidativo o disminución de la defensa antioxidante ${ }^{12,23}$. Un estudio en pacientes diabéticos tipo 2 encontró una correlación positiva entre la lipoperoxidación inducida por el estrés y la externalización de la fosfatidilserina ${ }^{34}$.

\section{Formación de la ceramida y la eriptosis}

La ceramida es un importante lípido que actúa como segundo mensajero en muchos procesos celulares, incluyendo la apoptosis y la senescencia. Se obtiene de la hidrólisis de la esfingomielina a través de la acción de la enzima esfingomielinasa ácida, la cual origina la fosfocolina y la ceramida. Dicha enzima, no ha sido reportada como parte del proteoma de los eritrocitos, pero pueden estar expuestos a: la esfingomielinasa ácida secretada por el endotelio vascular, los leucocitos y las plaquetas. En el eritrocito, la ceramida dificulta las interacciones entre la membrana celular y el citoesqueleto, alterando la integralidad de la primera, favoreciendo de esta manera la exposición de la fosfatidilserina. La secreción de esta enzima puede estar aumentada en diversas situaciones incluyendo: la diabetes, la sepsis, las enfermedades cardiovasculares y las pulmonares, entre otras $^{35,36}$.

La formación aumentada de la ceramida también se genera durante el estrés osmótico (fig. 1), en donde los eritrocitos activan la fosfolipasa A2 (PLA2), generando los lisoderivados que son transformados por el factor activador de plaquetas (PFA) ${ }^{35}$, el cual es un mediador de los fosfolípidos, involucrado en la regulación de: la inflamación, la trombosis, la aterogénesis y la función cardiovascular. En este mecanismo, se activa posiblemente una esfingomielinasa ácida que genera la ceramida por hidrólisis de la esfingomielina ${ }^{9,37}$. Estos procesos propician la vesiculización de la membrana celular estimulando la translocación de los fosfolípidos, desde su cara interna, produciendo la exposición de la fosfatidilserina, para luego ser reconocidos y degradados por los macrófagos que poseen receptores específicos para la fosfatidilserina. La acción de la PLA2, también genera el ácido araquidónico a partir de la fosfatidilcolina, dicho ácido es convertido a prostaglandina E2 por acción de la enzima ciclooxigenasa, la cual estimula el canal catiónico que permite la entrada de $\mathrm{Ca}^{2+}$ (fig. 1$)^{24,35,36,38}$.

\section{Adherencia de la fosfatidilserina a las células endoteliales}

Numerosos estudios indican que la inducción de la eriptosis conduce a un aumento significativo del número de eritrocitos firmemente adheridos a las células del endotelio vascular. Así mismo, las alteraciones de las proteínas de la membrana de los eritrocitos pueden propiciar enfermedades trombóticas ${ }^{1,2,16,19,39-41}$. Un estudio reciente encontró que las células eriptóticas que exponen la fosfatidilserina se 


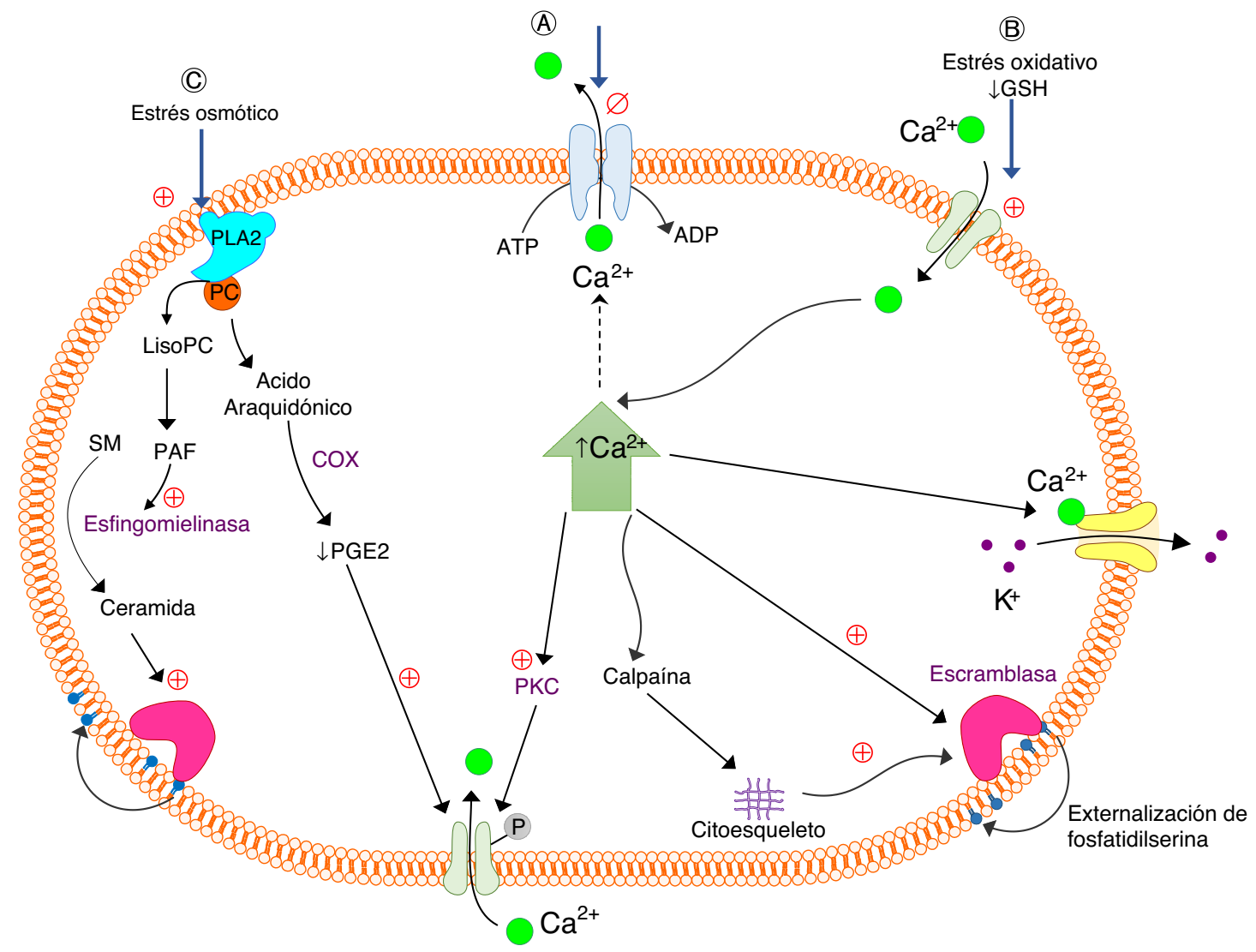

Figura 1 Señalización celular de los procesos de la eriptosis. El estímulo clave para la eriptosis en los tres procesos (A, B y C) esquematizados en la figura es el aumento de $\mathrm{Ca}^{2+}$ intracelular, pero cada uno se explica por vías diferentes. A. Estrés energético: disminución de ATP que reduce la acción de la ATPasa de calcio y en consecuencia disminuye la salida de $\mathrm{Ca}^{2+}$. Activación de PKC que fosforila proteínas de la membrana que permiten la entrada de $\mathrm{Ca}^{2+}$. B. Estrés oxidativo: disminución de GSH y activación de los canales catiónicos. C. Estrés osmótico: activación de la PLA2, que libera ácido araquidónico de fosfatidilcolina, para generar PGE2, que activa los canales de $\mathrm{Ca}^{2+}$. Activación de los canales de $\mathrm{K}+$ dependientes de $\mathrm{Ca}^{2+}$, con la subsiguiente pérdida de $\mathrm{Cl}-$ y $\mathrm{H}_{2} \mathrm{O}$, generando contracción en el eritrocito. Los tres procesos esquematizados estimulan la translocación de fosfolípidos de la membrana, produciendo la exposición o externalización de PS por medio de una escramblasa sensible a Ca ${ }^{2+}$. Glutatión reducido (GSH); fosfolipasa A2 (PLA2); fosfatidilcolina (PC); prostaglandina E2 (PGE2); esfingomielina (SM); factor de agregación plaquetario (PAF); ciclooxigenasa (COX); proteína quinasa dependiente de calcio (PKC); estimulación $(\oplus)$; inhibición $(\emptyset)$. Adaptado de Herlax y col. 2011.
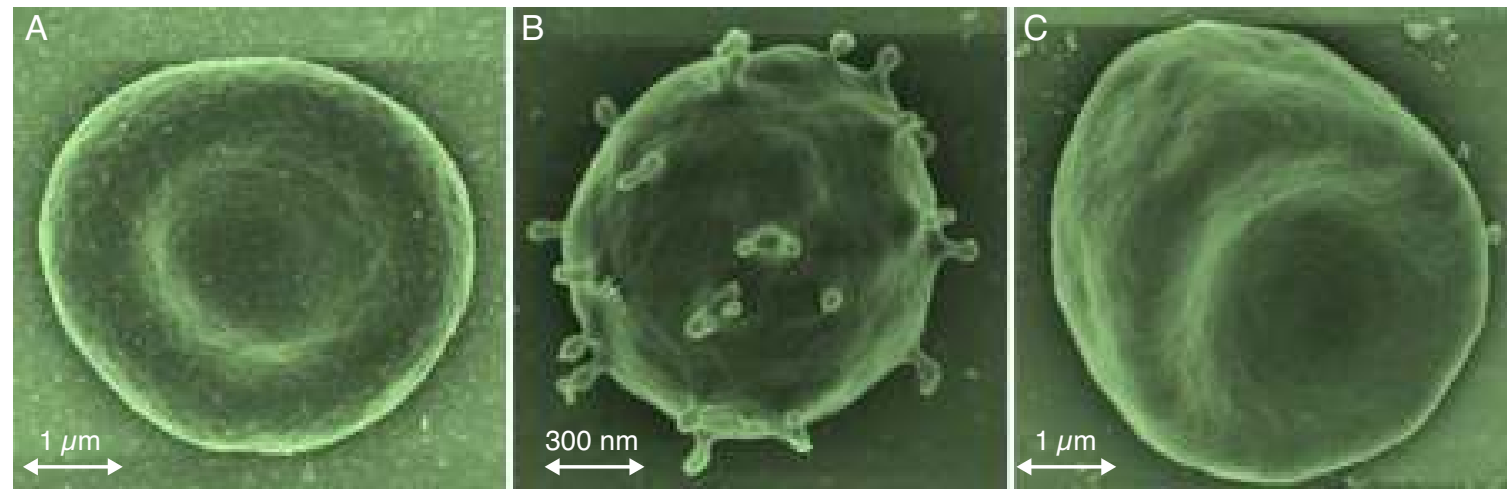

Figura 2 Cambios morfológicos en la eriptosis. A) Eritrocitos normales: forma bicóncava discoidal. B) Eritrocitos en forma de esferocitos con formación de microvesículas. C. Eritrocitos en forma de estomatocitos inducidos por estrés oxidativo. Las formas eriptóticas de esferocitos y equinocitos exponen fosfatidilserina y aumentan la probabilidad de adhesión al endotelio y la formación de trombos. Adaptada de Vittori y col. 2012. 
adherían con facilidad al endotelio vascular a través de la proteína transmembrana $\mathrm{CXCL} 16^{11}$. Ésta es una quimioquina expresada en las células endoteliales que ha sido implicada en el proceso aterosclerótico por participar como receptor de las lipoproteínas de baja densidad oxidadas (LDLox) ${ }^{42,43}$. Por tanto, las interacciones PS-CXCL16 aumentan la adhesividad de los eritrocitos, lo cual puede contribuir a la fisiopatología de las enfermedades cardiovasculares en los casos que exista eriptosis excesiva.

Se ha sugerido que el nivel circulante de CXCL16 podría ser un predictor de mortalidad a largo plazo en los síndromes coronarios agudos. Este receptor también es expresado en las células inflamatorias como las células dendríticas, los linfocitos $\mathrm{T}$ y los macrófagos cargados de lípidos en las placas ateroscleróticas ${ }^{44,45}$. La CXCL16 es fuertemente estimulada por las citoquinas proinflamatorias como el TNF- $\alpha$ e IFN- $\gamma^{46}$, los cuales son mediadores asociados con enfermedades inflamatorias o isquemia ${ }^{11}$. Los eritrocitos que exponen la fosfatidilserina aumentan su adhesividad al endotelio en enfermedades asociadas con un mayor riesgo de complicaciones cardiovasculares, tales como: la diabetes o la insuficiencia renal crónica ${ }^{30,47,48}$.

\section{Influencia de los fosfolípidos en las enfermedades cardiovasculares}

La perturbación de la simetría de los fosfolípidos de la membrana de los eritrocitos puede inducir cambios morfológicos y externalización de la fosfatidilserina, y en última instancia esta puede conducir a la activación trombogénica de los eritrocitos ${ }^{2}$. Los fosfolípidos son una clase de lípidos complejos que se componen de: dos ácidos grasos, una unidad de glicerol, un grupo fosfato y una molécula polar ${ }^{49}$. En el eritrocito, por acción de la fosfolipasa $\mathrm{D}$, la fosfatidilcolina genera el ácido fosfatídico ${ }^{50}$. El aumento de este último y de la actividad de la fosfolipasa $D$ ha sido reportada en múltiples enfermedades como: la inflamación, la diabetes, la aterosclerosis, la hipertensión y los eventos trombóticos; lo que sugiere un mayor riesgo para las enfermedades cardiovasculares ${ }^{50,51}$. El ácido fosfatídico afecta: la proliferación celular, la reorganización del citoesqueleto y el tráfico vesicular, además, puede inducir actividades trombogénicas. Éste actúa a través de la activación de la PKC dependiente de $\mathrm{Ca}^{2+}$, mediando con ello la exposición de la fosfatidilserina con la consecuente eriptosis (fig. 3$)^{30}$. Se ha sugerido que la activación de PKC puede influir en la integridad del citoesqueleto y las funciones de los eritrocitos, lo cual está mediado por la fosforilación de algunas proteínas de la membrana?.

La exposición de la fosfatidilserina proporciona un sitio de ensamblaje para las enzimas procoagulantes, con la consecuente generación de la trombina que facilita la hemostasia ${ }^{17,52}$. Otros lípidos endógenos como: el ácido araquidónico, las prostaglandinas y el factor activador de las plaquetas pueden inducir la exposición de este fosfolípido en los eritrocitos ${ }^{30}$.

En un modelo in vivo con ratas, la administración de ácido fosfatídico indujo aumento en la formación de trombos, con un efecto dependiente de la concentración del mismo ${ }^{30}$. Adicionalmente, el ácido fosfatídico puede originar el ácido lisofosfatídico por acción de la PLA2. Este último, también puede favorecer la eriptosis y actuar como una molécula aterogénica y trombogénica ${ }^{2,30}$. Generalmente, varios estudios han reportado que la relación entre la exposición de la fosfatidilserina y la microvesiculación están mediados por el aumento del calcio libre intracelular ${ }^{38}$. Sin embargo, otros autores han reportado que el ácido lisofosfatídico favorece la activación de PKC independiente del calcio. Otro aspecto relevante del ácido fosfatídico y el ácido lisofosfatídico, es el efecto inhibidor sobre la actividad de la flipasa, la cual es una proteína importante en el mantenimiento de la asimetría de la membrana ${ }^{2,30}$.

El ácido fosfatídico puede ser liberado por diversos estímulos, incluyendo: mediadores inflamatorios, hormonas y agonistas que participan en la activación de la fosfolipasa D en: los cardiomiocitos, las plaquetas, los neutrófilos y los eritrocitos ${ }^{47,53}$. Los eritrocitos que exponen la fosfatidilserina se vuelven más adhesivos a las células endoteliales siendo más propensos a la agregación eritrocitaria. Dichos eventos pueden contribuir a un mayor riesgo de desarrollar la formación de trombos, afectando con ello el sistema cardiovascular $^{30}$.

\section{Los metales pesados en la enfermedad cardiovascular}

Aunque pocos estudios han centrado su atención en los efectos tóxicos de los metales pesados en el sistema cardiovascular, estudios recientes demuestran la asociación del mercurio con: la hipertensión, la aterosclerosis, el infarto del miocardio y la enfermedad arterial coronaria ${ }^{54-58}$. Las teorías bioquímicas más aceptadas hasta la fecha indican una posible inducción del proceso de muerte celular de los eritrocitos por el estrés oxidativo, los cuales exponen la fosfatidilserina. Algunos estudios experimentales in vivo (ratas) evidenciaron que la exposición al mercurio induce la disfunción endotelial en las arterias coronarias ${ }^{54,55,59}$.

Los efectos del mercurio en el sistema cardiovascular parecen ser dependientes tanto de la dosis como del tiempo de exposición. Estudios en humanos han reportado que la exposición crónica al mercurio puede aumentar la resistencia vascular e inducir la hipertensión ${ }^{56}$. Por tanto, la presencia de este metal en el organismo puede ser considerado un factor de riesgo para las enfermedades cardiovasculares. La gravedad de la exposición al mercurio se debe a que tiene alta afinidad por grupos tioles o sulfhidrilos de las proteínas, lo que conlleva a la inactivación de numerosas reacciones enzimáticas, aminoácidos y antioxidantes, con la subsiguiente disminución de la defensa antioxidante y aumento del estrés oxidativo ${ }^{57}$.

Por otra parte, investigaciones in vitro concluyen que la exposición a dosis bajas de $\mathrm{Hg}^{2+}(0,25$ - $5 \mu \mathrm{M})$ conducen a cambios en la morfología de los eritrocitos ${ }^{28,55,58}$, acompañado de la generación de microvesículas y la exposición de la fosfatidilserina. Las interacciones del $\mathrm{Hg}^{2+}$ con las proteínas pueden ser un mediador para el aumento del $\mathrm{Ca}^{2+}$ intracelular libre y disminución del ATP, con la consecuente apoptosis del eritrocito ${ }^{28}$. Hasta la fecha el mecanismo de inducción de translocación de la fosfatidilserina por parte del mercurio no está claro. Una hipótesis sugiere la unión de estos iones metálicos a hPLSCR1 (escramblasa de fosfolípidos humana 1), lo cual favorece la exposición de la 


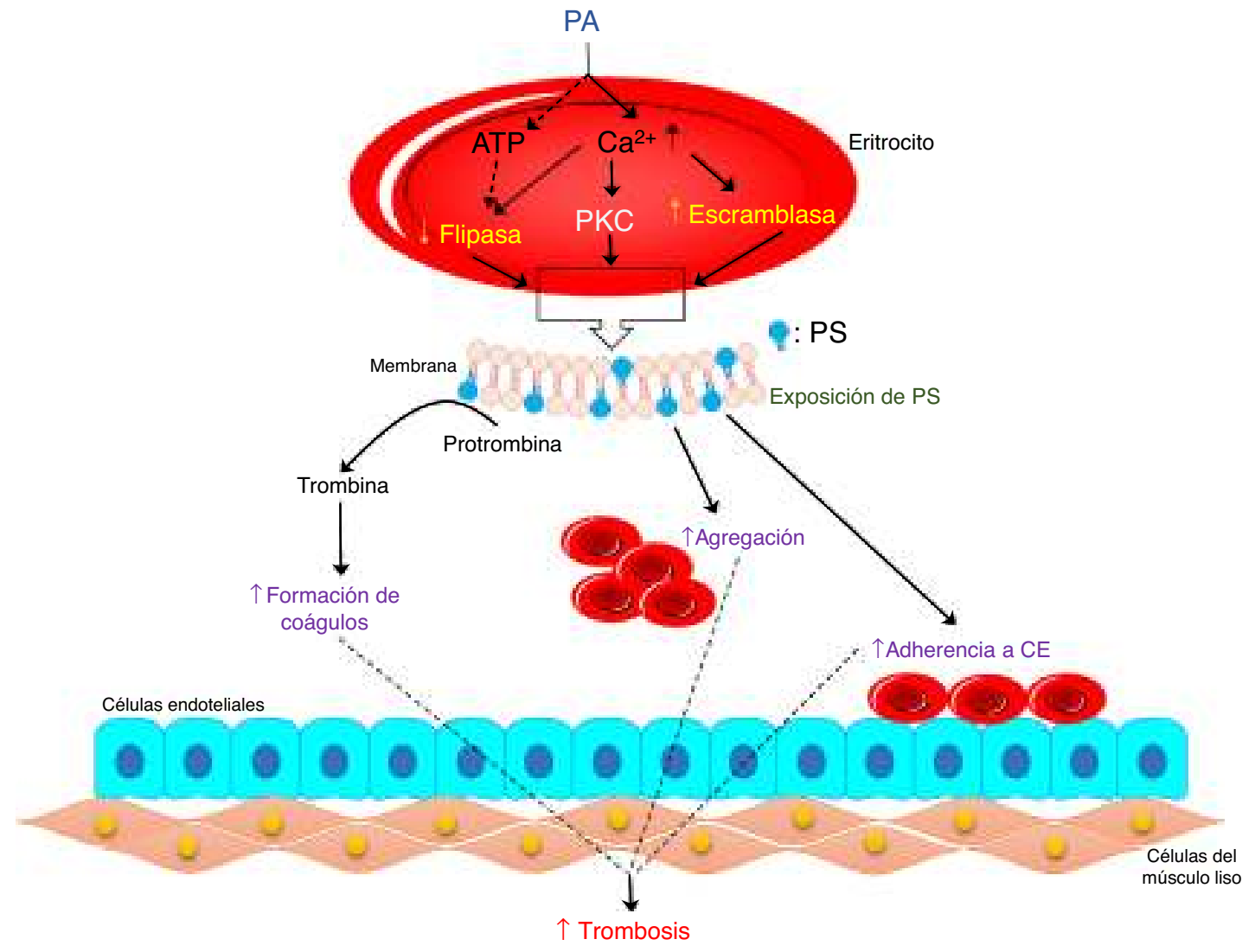

Figura 3 Actividad trombogénica del ácido fosfatídico en eritrocitos humanos. Los eritrocitos responden a PA endógeno para expresar PS en su superficie (eriptosis), lo cual está mediada por una disminución de ATP, aumento de Ca ${ }^{2+}$, y activación de PKC, que culmina con la activación de la escramblasa e inhibición de la flipasa. Los eritrocitos estimulados con PA pueden inducir la generación de trombina en el plasma y aumentar la agregación y adhesión de los eritrocitos a las células endoteliales, contribuyendo a la formación de trombos. PA: ácido fosfatídico. PS: fosfatidilserina. PKC: proteína quinasa C. CE: célula endotelial. Adaptado de Noh y col. 2010.

fosfatidilserina ${ }^{59}$. La exposición de este fosfolípido puede servir como un sitio para el anclaje de un complejo protrombinasa y tenasa, dando lugar a la generación de trombina con cambios en la forma del eritrocito que pueden fomentar el aumento de la adherencia de estas células a la pared vascular y la formación de trombos ${ }^{28}$. Todas estas evidencias muestran cada vez una mayor relación del mercurio con las enfermedades cardiovasculares. No obstante, se necesitan más estudios para comprender totalmente los mecanismos implicados en los efectos del mercurio en el sistema cardiovascular.

\section{Inhibidores de la eriptosis}

La inhibición de los canales catiónicos del calcio por algunas sutancias como: el amiloride y el etilisopropilamiloride ${ }^{60}$, han mostrado una prevención del proceso de muerte celular del eritrocito. En otros estudios, la dopamina, el isoproterenol y la epinefrina han mostrado similares efectos ${ }^{61}$. Lo anterior se explica porque el aumento del $\mathrm{Ca}^{2+}$ citosólico y la pérdida celular del $\mathrm{K}^{+}$participan en la activación de la escramblasa de los eritrocitos y por consiguiente el proceso de eriptosis. Por otro lado, otros estudios reportan que el clotrimazol o la caribdotoxina aumentan los niveles del $\mathrm{K}^{+}$ contrarrestando la pérdida de este catión e inhibiendo el proceso de eriptosis ${ }^{62}$.

\section{Otras enfermedades asociadas a la eriptosis}

La eriptosis se ha relacionado con una variedad de condiciones clínicas o enfermedades, incluyendo: el síndrome urémico hemolítico ${ }^{63}$, la sepsis ${ }^{64}$, la malaria ${ }^{65}$, las células falciformes, la $\beta$ talasemia, la deficiencia de glucosa6-fosfato deshidrogenasa, la esferocitosis hereditaria, la hemoglobinuria paroxística nocturna, el síndrome mielodisplásico, el agotamiento de fosfato, la deficiencia de hierro, la insuficiencia renal, la insuficiencia cardíaca, etc.

\section{Síndrome urémico hemolítico}

El síndrome urémico hemolítico (SUH), se caracteriza por la anemia hemolítica con presencia de fragmentados eritrocitarios, trombocitopenia y falla renal aguda ${ }^{63}$. Frecuentemente, el SUH es causado por las verotoxinas producidas por Escherichia coli $0157: \mathrm{H}^{66}$, y de forma infrecuente, por un defecto genético de las proteínas del complemento o las proteasas asociadas al factor de Von Willebrand ${ }^{67,68}$. El SUH puede también ser causado por 
ciertos fármacos incluyendo: la ciclosporina, los anticonceptivos orales, la quinina y la cocaína ${ }^{69}$. Los estudios realizados por Lang, et al. ${ }^{63}$, muestran que el plasma de pacientes con SUH provoca la muerte suicida de los eritrocitos, demostrando con ello que la exposición de eritrocitos a plasma de pacientes con SUH produce: el ingreso del $\mathrm{Ca}^{2+}$, la formación de ceramida y la exposición de PS. Lo anterior favorece la unión a receptores de PS expresados por los macrófagos y su fagocitosis, eliminando de esta manera a los eritrocitos afectados.

\section{Sepsis}

Es una condición clínica asociada a infecciones con una amplia variedad de patógenos. Entre las secuelas características de la sepsis se puede nombrar el desarrollo de la anemia; no por una disminución en la formación de los eritrocitos sino por una eliminación acelerada de los mismos de la circulación ${ }^{70}$. Cuando los eritrocitos de voluntarios sanos se exponen al plasma de pacientes sépticos o sobrenadantes de patógenos, se incrementa la exposición de PS. El efecto del plasma de pacientes sépticos sobre la concentración del $\mathrm{Ca}^{2+}$ es moderado como para ser responsable de la fuerte estimulación de la exposición de PS. En este caso, es probable que la formación de la ceramida por ruptura de SM mediada por la esfingomielinasa sea el factor más importante. Varias bacterias patógenas producen las esfingomielinasas que estimulan la formación de la ceramida. La hemólisis inducida por determinados patógenos puede de manera similar contribuir a la eliminación acelerada de los eritrocitos y producir la anemia en pacientes sépticos, como se ha demostrado luego de la infección por Clostridium perfringens $^{64}$.

\section{La malaria}

El patógeno causante de la malaria es el Plasmodium falciparum, que entra en el eritrocito escapando del reconocimiento por el sistema inmune del huésped. Es por eso que el Plasmodium falciparum depende de la activación de canales iónicos en el eritrocito que le permiten incorporar nutrientes, $\mathrm{Na}^{+}$y $\mathrm{Ca}^{+2}$. A su vez, activa los canales en el eritrocito por el estrés oxidativo produciendo la apertura de los canales catiónicos permeables al $\mathrm{Ca}^{+2}$ que estimulan la eriptosis. Mientras que los canales se requieren para la sobrevida, la replicación y la maduración del Plasmodium falciparum en el eritrocito, también limitan la vida del eritrocito infectado y en consecuencia del patógeno intracelular ${ }^{65}$.

\section{Deficiencia de hierro}

La deficiencia de hierro ocasiona la anemia, la cual en parte es debida a una disminución de la vida media del eritrocito. Está aceptado que la anemia por deficiencia de hierro es el resultado de una eritropoyesis disminuida ${ }^{71}$. Sin embargo, existen algunas evidencias que indican que la anemia en este caso también es ocasionada por una vida media disminuida de los eritrocitos deficientes en hierro. El contenido reducido de hemoglobina en eritrocitos deficientes en hierro lleva a una disminución de la presión osmótica coloidal, y por tanto, a una reducción del volumen celular. Esta disminución de volumen es responsable de un aumento en la actividad de los canales catiónicos no selectivos. Aunque el ingreso del $\mathrm{Na}^{+}$a través de este canal produce un incremento de volumen, la entrada del $\mathrm{Ca}^{+2}$ ejerce un efecto opuesto. El ingreso del $\mathrm{Ca}^{+2}$ y la activación del canal Gardos contribuyen a la activación de la eriptosis. Además, dado que los eritrocitos deficientes en hierro son más sensibles al estrés oxidativo, esto induce la activación de los canales catiónicos ${ }^{24}$. Esta condición puede agravarse en pacientes con insuficiencia cardiaca o insuficiencia renal por incremento de la eriptosis ${ }^{32,72}$.

Por otra parte, los nuevos mecanismos observados de la eriptosis presumen que pueden tener una relación intrínseca con la producción de enfermedades cardiovasculares como: la trombosis, los infartos, la ateroesclerosis o la hipertensión; dado que los eritrocitos que exponen la fosfatidilserina (PS), se vuelven más adhesivos a las células endoteliales, siendo más propensos al proceso de agregación eritrocitaria dando origen a las enfermedades cardiovasculares ${ }^{30}$.

\section{Conclusiones}

Las investigaciones en este campo de estudio señalan que el eritrocito posee una maquinaria bioquímica compleja, permitiendo la autodestrucción programada de los eritrocitos lesionados en circulación antes de la senectud.

La muerte del eritrocito consta de varias vías de señalización que incluyen: la formación de la ceramida, el aumento del calcio intracelular y la activación de la escramblasa. Cabe resaltar que el punto clave de la eriptosis es la exposición a la fosfatidilserina, que posee receptores de reconocimiento por parte de los macrófagos para su eliminación. La eriptosis acelerada ha sido blanco para numerosos estudios que han relacionado la exposición de la fosfatidilserina como un vínculo molecular para la adhesión a la pared vascular, con la consecuente formación de trombos. El conocimiento de los nuevos mecanismos que subyacen a la formación de trombos puede ser importante para la prevención clínica de las enfermedades cardiovasculares. Sin embargo, es necesario llevar a cabo otros estudios que busquen esclarecer la señalización de este proceso y sus implicaciones en la actividad procoagulante por parte de los eritrocitos eriptóticos.

\section{Responsabilidades éticas}

Protección de personas y animales. Los autores declaran que para esta investigación no se han realizado experimentos en seres humanos ni en animales.

Confidencialidad de los datos. Los autores declaran que en este artículo no aparecen datos de pacientes.

Derecho a la privacidad y consentimiento informado. Los autores declaran que en este artículo no aparecen datos de pacientes. 


\section{Conflicto de intereses}

Los autores declaran no tener conflictos de intereses.

\section{Agradecimientos}

\section{A la Universidad de Cartagena especialmente a la Vicerrec- toría de Investigaciones en el plan de fortalecimientos de grupos de investigación.}

\section{Bibliografía}

1. Andrews DA, Low PS. Role of red blood cells in thrombosis. Curr Opin Hematol. 1999;6(2):76-82.

2. Chung SM, Bae ON, Lim KM, Noh JY, Lee MY, Jung YS, et al. Lysophosphatidic acid induces thrombogenic activity through phosphatidylserine exposure and procoagulant microvesicle generation in human erythrocytes. Arterioscler Thromb Vasc Biol. 2007;27(2):414-21.

3. Ho CH. The hemostatic effect of adequate red cell transfusion in patients with anemia and thrombocytopenia. Transfusion. 1996;36(3):290.

4. Golden C. Polycythemia vera: a review. Clin J Oncol Nurs. 2003;7(5):553-6.

5. Berg CP, Engels IH, Rothbart A, Lauber K, Renz A, Schlosser $\mathrm{SF}$, et al. Human mature red blood cells express caspase- 3 and caspase-8, but are devoid of mitochondrial regulators of apoptosis. Cell Death Differ. 2001;8(12):1197-206.

6. Bratosin D, Estaquier J, Petit F, Arnoult D, Quatannens B, Tissier JP, et al. Programmed cell death in mature erythrocytes: a model for investigating death effector pathways operating in the absence of mitochondria. Cell Death Differ. $2001 ; 8(12): 1143-56$

7. Lang KS, Duranton C, Poehlmann H, Myssina S, Bauer C, Lang F, et al. Cation channels trigger apoptotic death of erythrocytes. Cell Death Differ. 2003;10(2):249-56.

8. Lang KS, Lang PA, Bauer C, Duranton C, Wieder T, Huber SM, et al. Mechanisms of suicidal erythrocyte death. Cell Physiol Biochem. 2005;15(5):195-202.

9. Neidlinger NA, Larkin SK, Bhagat A, Victorino GP, Kuypers FA. Hydrolysis of phosphatidylserine-exposing red blood cells by secretory phospholipase A2 generates lysophosphatidic acid and results in vascular dysfunction. J Biol Chem. 2006;281(2):775-81

10. Abed M, Towhid ST, Mia S, Pakladok T, Alesutan I, Borst 0 , et al. Sphingomyelinase-induced adhesion of eryptotic erythrocytes to endothelial cells. Am J Physiol Cell Physiol. 2012;303(9):C991-9.

11. Borst O, Abed M, Alesutan I, Towhid ST, Qadri SM, Foller M, et al. Dynamic adhesion of eryptotic erythrocytes to endothelial cells via CXCL16/SR-PSOX. Am J Physiol Cell Physiol. 2012;302(4):C644-51.

12. Lang F, Lang KS, Lang PA, Huber SM, Wieder T. Mechanisms and significance of eryptosis. Antioxid Redox Signal. 2006;8(7-8):1183-92.

13. Lang F, Gulbins E, Lerche H, Huber SM, Kempe DS, Foller M. Eryptosis, a window to systemic disease. Cell Physiol Biochem. 2008;22(5-6):373-80.

14. Lang F, Lang E, Foller M. Physiology and pathophysiology of eryptosis. Transfus Med Hemother. 2012;39(5):308-14.

15. Lang E, Lang F. Mechanisms and pathophysiological significance of eryptosis, the suicidal erythrocyte death. Semin Cell Dev Biol. 2015.

16. Zwaal RF, Schroit AJ. Pathophysiologic implications of membrane phospholipid asymmetry in blood cells. Blood. 1997;89(4):1121-32.
17. Zwaal RF, Comfurius P, Bevers EM. Surface exposure of phosphatidylserine in pathological cells. Cell Mol Life Sci. 2005;62(9):971-88.

18. Stevic I, Chan HH, Berry LR, Chander A, Chan AK. Inhibition of the prothrombinase complex on red blood cells by heparin and covalent antithrombin-heparin complex. J Biochem. 2013;153(1):103-10.

19. Closse C, Dachary-Prigent J, Boisseau MR. Phosphatidylserinerelated adhesion of human erythrocytes to vascular endothelium. Br J Haematol. 1999;107(2):300-2.

20. Martin DW, Jesty J. Calcium stimulation of procoagulant activity in human erythrocytes. ATP dependence and the effects of modifiers of stimulation and recovery. J Biol Chem. 1995;270(18):10468-74.

21. de Jong K, Rettig MP, Low PS, Kuypers FA. Protein kinase C activation induces phosphatidylserine exposure on red blood cells. Biochemistry. 2002;41(41):12562-7.

22. Beleznay Z, Zachowski A, Devaux PF, Ott P. Characterization of the correlation between ATP-dependent aminophospholipid translocation and Mg2 + -ATPase activity in red blood cell membranes. Eur J Biochem. 1997;243(1-2):58-65.

23. Lang F, Lang KS, Lang PA, Huber SM, Wieder T. Osmotic shockinduced suicidal death of erythrocytes. Acta Physiol (Oxf). 2006;187(1-2):191-8.

24. Herlax V, Vazquez R, Mate S, Bakás L. Eriptosis, la muerte suicida de eritrocitos: mecanismo y enfermedades asociadas. Acta Bioquímica Clínica Latinoamericana. 2011;45(2):287-96.

25. Sopjani M, Foller M, Dreischer P, Lang F. Stimulation of eryptosis by cadmium ions. Cell Physiol Biochem. 2008;22(1-4): 245-52.

26. Lang F, Lang PA, Lang KS, Brand V, Tanneur V, Duranton C, et al. Channel-induced apoptosis of infected host cells-the case of malaria. Pflugers Arch. 2004;448(3):319-24.

27. Biswas D, Banerjee M, Sen G, Das JK, Banerjee A, Sau TJ, et al. Mechanism of erythrocyte death in human population exposed to arsenic through drinking water. Toxicol Appl Pharmacol. 2008;230(1):57-66

28. Lim KM, Kim S, Noh JY, Kim K, Jang WH, Bae ON, et al. Low-level mercury can enhance procoagulant activity of erythrocytes: a new contributing factor for mercury-related thrombotic disease. Environ Health Perspect. 2010;118(7):928-35.

29. Kaestner L, Steffen P, Nguyen DB, Wang J, Wagner-Britz L, Jung A, et al. Lysophosphatidic acid induced red blood cell aggregation in vitro. Bioelectrochemistry. 2012;87:89-95.

30. Noh JY, Lim KM, Bae ON, Chung SM, Lee SW, Joo KM, et al. Procoagulant and prothrombotic activation of human erythrocytes by phosphatidic acid. Am J Physiol Heart Circ Physiol. 2010;299(2):H347-55.

31. Abed M, Balasaheb S, Towhid ST, Daniel C, Amann K, Lang F. Adhesion of annexin 7 deficient erythrocytes to endothelial cells. PLoS One. 2013;8(2):e56650.

32. Mahmud H, Ruifrok WP, Westenbrink BD, Cannon MV, VreeswijkBaudoin I, van Gilst WH, et al. Suicidal erythrocyte death, eryptosis, as a novel mechanism in heart failure-associated anaemia. Cardiovasc Res. 2013;98(1):37-46.

33. Mohanty JG, Nagababu E, Rifkind JM. Red blood cell oxidative stress impairs oxygen delivery and induces red blood cell aging. Front Physiol. 2014;5:84.

34. Calderon-Salinas JV, Munoz-Reyes EG, Guerrero-Romero JF, Rodriguez-Moran M, Bracho-Riquelme RL, Carrera-Gracia MA, et al. Eryptosis and oxidative damage in type 2 diabetic mellitus patients with chronic kidney disease. Mol Cell Biochem. 2011;357(1-2):171-9.

35. Lang PA, Kempe DS, Tanneur V, Eisele K, Klarl BA, Myssina $S$, et al. Stimulation of erythrocyte ceramide formation by platelet-activating factor. J Cell Sci. 2005;118 Pt 6:1233-43.

36. Dinkla S, Wessels K, Verdurmen WP, Tomelleri C, Cluitmans JC, Fransen $\mathrm{J}$, et al. Functional consequences of 
sphingomyelinase-induced changes in erythrocyte membrane structure. Cell Death Dis. 2012;3:e410.

37. Goggel R, Winoto-Morbach S, Vielhaber G, Imai Y, Lindner $\mathrm{K}$, Brade L, et al. PAF-mediated pulmonary edema: a new role for acid sphingomyelinase and ceramide. Nat Med. 2004;10(2):155-60.

38. Kaestner L, Tabellion W, Lipp P, Bernhardt I. Prostaglandin E2 activates channel-mediated calcium entry in human erythrocytes: an indication for a blood clot formation supporting process. Thromb Haemost. 2004;92(6):1269-72.

39. Wood BL, Gibson DF, Tait JF. Increased erythrocyte phosphatidylserine exposure in sickle cell disease: flow-cytometric measurement and clinical associations. Blood. 1996;88(5):1873-80.

40. Gallagher PG, Chang SH, Rettig MP, Neely JE, Hillery CA, Smith BD, et al. Altered erythrocyte endothelial adherence and membrane phospholipid asymmetry in hereditary hydrocytosis. Blood. 2003;101(11):4625-7.

41. Pandolfi A, Di Pietro N, Sirolli V, Giardinelli A, Di Silvestre S, Amoroso L, et al. Mechanisms of uremic erythrocyte-induced adhesion of human monocytes to cultured endothelial cells. J Cell Physiol. 2007;213(3):699-709.

42. Gough PJ, Garton KJ, Wille PT, Rychlewski M, Dempsey PJ, Raines EW. A disintegrin and metalloproteinase 10-mediated cleavage and shedding regulates the cell surface expression of CXC chemokine ligand 16. J Immunol. 2004;172(6):3678-85.

43. Shimaoka T, Seino K, Kume N, Minami M, Nishime C, Suematsu $M$, et al. Critical role for CXC chemokine ligand 16 (SR-PSOX) in Th1 response mediated by NKT cells. J Immunol. 2007;179(12):8172-9.

44. Minami M, Kume N, Shimaoka T, Kataoka H, Hayashida K, Yonehara S, et al. Expression of scavenger receptor for phosphatidylserine and oxidized lipoprotein (SR-PSOX) in human atheroma. Ann N Y Acad Sci. 2001;947:373-6.

45. Minami M, Kume N, Shimaoka T, Kataoka H, Hayashida K, Akiyama $Y$, et al. Expression of SR-PSOX, a novel cell-surface scavenger receptor for phosphatidylserine and oxidized LDL in human atherosclerotic lesions. Arterioscler Thromb Vasc Biol. 2001;21(11):1796-800.

46. Abel S, Hundhausen C, Mentlein R, Schulte A, Berkhout TA, Broadway N, et al. The transmembrane CXC-chemokine ligand 16 is induced by IFN-gamma and TNF-alpha and shed by the activity of the disintegrin-like metalloproteinase ADAM10. J Immunol. 2004;172(10):6362-72.

47. Bonomini M, Sirolli V, Settefrati N, Dottori S, Di Liberato L, Arduini A. Increased erythrocyte phosphatidylserine exposure in chronic renal failure. J Am Soc Nephrol. 1999;10(9):1982-90.

48. Manodori AB, Kuypers FA. Altered red cell turnover in diabetic mice. J Lab Clin Med. 2002;140(3):161-5.

49. Yang Y, Jang H-J, Ryu S, Suh P-G. Phospholipases in Health and Disease. In: Tappia PS, Dhalla NS, editors. Phospholipases in Health and Disease: Springer New York; 2014. p. 3-38.

50. Tappia PS, Dhalla NS, Tappia P, Dhalla N. Alterations in Phospholipase D During the Development of Myocardial Disease. Springer New York: Phospholipases in Health and Disease; 2014. p. 381-93.

51. Touyz RM, Schiffrin EL. Increased generation of superoxide by angiotensin II in smooth muscle cells from resistance arteries of hypertensive patients: role of phospholipase Ddependent $\mathrm{NAD}(\mathrm{P}) \mathrm{H}$ oxidase-sensitive pathways. J Hypertens. 2001;19(7):1245-54.

52. Kuypers FA, Larkin SK, Emeis JJ, Allison AC. Interaction of an annexin $\mathrm{V}$ homodimer (Diannexin) with phosphatidylserine on cell surfaces and consequent antithrombotic activity. Thromb Haemost. 2007;97(3):478-86.

53. Wang X, Devaiah SP, Zhang W, Welti R. Signaling functions of phosphatidic acid. Prog Lipid Res. 2006;45(3):250-78.

54. Houston MC. The role of mercury and cadmium heavy metals in vascular disease, hypertension, coronary heart disease, and myocardial infarction. Altern Ther Health Med. 2007;13(2):S128-33.

55. Furieri LB, Galan M, Avendano MS, Garcia-Redondo AB, Aguado A, Martinez S, et al. Endothelial dysfunction of rat coronary arteries after exposure to low concentrations of mercury is dependent on reactive oxygen species. $\mathrm{Br} \mathrm{J}$ Pharmacol. 2011;162(8):1819-31.

56. Garcia Gomez M, Boffetta P, Caballero Klink JD, Espanol S, Gomez Quintana J. [Cardiovascular mortality in mercury miners]. Med Clin (Barc). 2007;128(20):766-71.

57. Vassallo DV, Simoes MR, Furieri LB, Fioresi M, Fiorim J, Almeida EA, et al. Toxic effects of mercury, lead and gadolinium on vascular reactivity. Braz J Med Biol Res. 2011;44(9):939-46.

58. Suwalsky M, Ungerer B, Villena F, Cuevas F, Sotomayor CP. $\mathrm{HgCl} 2$ disrupts the structure of the human erythrocyte membrane and model phospholipid bilayers. J Inorg Biochem. 2000;81(4):267-73.

59. Shettihalli AK, Gummadi SN. Biochemical evidence for lead and mercury induced transbilayer movement of phospholipids mediated by human phospholipid scramblase 1 . Chem Res Toxicol. 2013;26(6):918-25.

60. Lang KS, Myssina S, Tanneur V, Wieder T, Huber SM, Lang F, et al. Inhibition of erythrocyte cation channels and apoptosis by ethylisopropylamiloride. Naunyn Schmiedebergs Arch Pharmacol. 2003;367(4):391-6.

61. Lang PA, Kempe DS, Akel A, Klarl BA, Eisele K, Podolski M, et al. Inhibition of erythrocyte "apoptosis" by catecholamines. Naunyn Schmiedebergs Arch Pharmacol. 2005;372(3):228-35.

62. Lang F, Birka C, Myssina S, Lang KS, Lang PA, Tanneur V, et al. Erythrocyte ion channels in regulation of apoptosis. Adv Exp Med Biol. 2004;559:211-7.

63. Lang PA, Beringer O, Nicolay JP, Amon O, Kempe DS, Hermle $T$, et al. Suicidal death of erythrocytes in recurrent hemolytic uremic syndrome. J Mol Med (Berl). 2006;84(5):378-88.

64. Kempe DS, Akel A, Lang PA, Hermle T, Biswas R, Muresanu J, et al. Suicidal erythrocyte death in sepsis. J Mol Med (Berl). 2007;85(3):273-81.

65. Brand VB, Sandu CD, Duranton C, Tanneur V, Lang KS, Huber SM, et al. Dependence of Plasmodium falciparum in vitro growth on the cation permeability of the human host erythrocyte. Cell Physiol Biochem. 2003;13(6):347-56.

66. Bitzan M, Bickford BB, Foster GH. Verotoxin (shiga toxin) sensitizes renal epithelial cells to increased heme toxicity: possible implications for the hemolytic uremic syndrome. J Am Soc Nephrol. 2004;15(9):2334-43.

67. Noris M, Remuzzi G. Genetic abnormalities of complement regulators in hemolytic uremic syndrome: how do they affect patient management? Nat Clin Pract Nephrol. 2005;1(1):2-3.

68. Le Quintrec M, Roumenina L, Noris M, Fremeaux-Bacchi V. Atypical hemolytic uremic syndrome associated with mutations in complement regulator genes. Semin Thromb Hemost. 2010;36(6):641-52.

69. Dlott JS, Danielson CF, Blue-Hnidy DE, McCarthy LJ. Druginduced thrombotic thrombocytopenic purpura/hemolytic uremic syndrome: a concise review. Ther Apher Dial. 2004;8(2):102-11.

70. Dellinger RP, Levy MM, Rhodes A, Annane D, Gerlach H, Opal SM, et al. Surviving Sepsis Campaign: international guidelines for management of severe sepsis and septic shock, 2012. Intensive Care Med. 2013;39(2):165-228.

71. Arndt U, Kaltwasser JP, Gottschalk R, Hoelzer D, Moller B. Correction of iron-deficient erythropoiesis in the treatment of anemia of chronic disease with recombinant human erythropoietin. Ann Hematol. 2005;84(3):159-66.

72. Abed M, Artunc F, Alzoubi K, Honisch S, Baumann D, Foller M, et al. Suicidal erythrocyte death in end-stage renal disease. J Mol Med (Berl). 2014;92(8):871-9. 